\title{
Mechanical thrombectomy versus intravenous thrombolysis for distal large-vessel occlusion: a systematic review and meta-analysis of observational studies
}

\author{
Muhammad Waqas, MBBS, ${ }^{1,2}$ Cathleen C. Kuo, BS, ${ }^{3}$ Rimal H. Dossani, MD, ${ }^{1,2}$ \\ Andre Monteiro, MD, ${ }^{1,2}$ Ammad A. Baig, MBBS, ${ }^{1,2}$ Modhi Alkhaldi, MD, ${ }^{4}$ Justin M. Cappuzzo, MD,, \\ Elad I. Levy, MD, MBA, ${ }^{1,2,5-7}$ and Adnan H. Siddiqui, MD, PhD ${ }^{1,2,5-7}$ \\ Departments of ${ }^{1}$ Neurosurgery and ${ }^{7}$ Radiology, ${ }^{3} \mathrm{Jacobs}$ School of Medicine and Biomedical Sciences, and ${ }^{5}$ Canon Stroke and \\ Vascular Research Center, University at Buffalo; ${ }^{2}$ Department of Neurosurgery, Gates Vascular Institute at Kaleida Health, \\ Buffalo; ${ }^{6} \mathrm{Jacobs}$ Institute, Buffalo, New York; and ${ }^{4}$ Imam Abdulrahman Bin Faisal University, Dammam, Saudi Arabia
}

\begin{abstract}
OBJECTIVE While several studies have compared the feasibility and safety of mechanical thrombectomy (MT) for distal large-vessel occlusion (LVO) strokes in patients, few studies have compared MT with intravenous thrombolysis (IVT) alone. The purpose of this systematic review was to compare the effectiveness and safety between MT and standard medical management with IVT alone for patients with distal LVOs.

METHODS PubMed, Google Scholar, Embase, Scopus, Web of Science, Ovid Medline, and Cochrane Library were searched in order to identify studies that directly compared MT with IVT for distal LVOs (anterior cerebral artery $A_{2}$, middle cerebral artery $\mathrm{M}_{3-4}$, and posterior cerebral artery $\mathrm{P}_{2-4}$ ). Primary outcomes of interest included a modified Rankin Scale (mRS) score of 0 to 2 at 90 days posttreatment, occurrence of symptomatic intracerebral hemorrhage (sICH), and all-cause mortality at 90 days posttreatment.
\end{abstract}

RESULTS Four studies representing a total of 381 patients were included in this meta-analysis. The pooled results indicated that the proportion of patients with an mRS score of 0 to 2 at 90 days (OR 1.16,95\% $\mathrm{Cl} 0.23-5.93 ; p=0.861$ ), the occurrence of $\mathrm{sICH}(\mathrm{OR} 2.45,95 \% \mathrm{Cl} 0.75-8.03 ; \mathrm{p}=0.140)$, and the mortality rate at 90 days $(\mathrm{OR} 1.73,95 \% \mathrm{Cl}$ $0.66-4.55 ; p=0.263$ ) did not differ between patients who underwent MT and those who received IVT alone.

CONCLUSIONS The meta-analysis did not demonstrate a significant difference between MT and standard medical management with regard to favorable outcome, occurrence of $\mathrm{sICH}$, or 90-day mortality. Prospective clinical trials are needed to further compare the efficacy of MT with IVT alone for distal vessel occlusion.

https://thejns.org/doi/abs/10.3171/2021.4.FOCUS21139

KEYWORDS distal large-vessel occlusion; mechanical thrombectomy; stroke; thrombolysis; symptomatic intracranial hemorrhage

$\mathrm{R}$ ANDOMIZED controlled trials have established the efficacy of mechanical thrombectomy (MT) in patients with acute ischemic stroke (AIS) due to large-vessel occlusion (LVO) ${ }^{1-5}$ The effectiveness of MT for distal LVOs is still open for debate as patients with distal occlusions, posterior circulation strokes, and tandem lesions were not represented in these studies. The American Heart Association (AHA)/American Stroke Association (ASA) 2019 update to the 2018 Guidelines for the Early Management of Patients with Acute Ischemic
Stroke provides a weak recommendation (class $2 b$ ) for MT in patients with an $\mathrm{M}_{2}$ occlusion and more distal occlusions. ${ }^{6}$

Distally located clots, which account for $25 \%$ to $40 \%$ of all AISs, produce heterogeneous clinical syndromes (mild symptoms vs permanent severe disability) and are associated with increased morbidity. ${ }^{7-9}$ A longer and tortuous course to the distal occlusions, smaller artery caliber, and fragility of arterial walls lead to an increase in the risk of vasospasm, dissection, and perforation. In their study of 69

ABBREVIATIONS ACA = anterior cerebral artery; AIS = acute ischemic stroke; IVT = intravenous thrombolysis; IV tPA = intravenous tissue plasminogen activator; LVO = large-vessel occlusion; MCA = middle cerebral artery; mRS = modified Rankin Scale; MT = mechanical thrombectomy; NIHSS = National Institutes of Health Stroke Scale; NOS = Newcastle-Ottawa Scale; PCA = posterior cerebral artery; PRISMA = Preferred Reporting Items for Systematic Reviews and Meta-Analyses; sICH = symptomatic intracerebral hemorrhage; $\mathrm{TICl}=$ Thrombolysis in Cerebral Infarction scale.

SUBMITTED March 1, 2021. ACCEPTED April 7, 2021.

INCLUDE WHEN CITING DOI: 10.3171/2021.4.FOCUS21139. 
patients in which $54 \%$ of patients had stent retriever treatment, 52\% had intraarterial thrombolysis, and $45 \%$ had thromboaspiration for distal vessel occlusions, Grossberg et al. reported an $83 \%$ rate of near-complete or complete reperfusion, with a $4 \%$ rate of parenchymal hematoma observed after endovascular thrombectomy ${ }^{10}$ Several studies also provided insight on the feasibility and safety profile of MT devices in distal vascular territories. ${ }^{11-13}$ However, these were generally small studies with preponderant occlusions of the proximal $\mathrm{M}_{2}$ segment rather than more distal, smaller vessels. Moreover, none of these studies had a control group treated medically with intravenous tissue plasminogen activator (IV tPA) to serve as a comparison for the MT-treated patients.

In the absence of randomized controlled trials, matched comparisons from multiple large registries and meta-analyses may provide the best evidence to compare MT with standard medical management using IV tPA for distal vessel occlusions. Therefore, we conducted a systematic review and meta-analysis to compare clinical outcomes and postoperative complications between MT and intravenous thrombolysis (IVT) for these occlusions.

\section{Methods}

This study was performed in accordance with Preferred Reporting Items for Systematic Reviews and MetaAnalyses (PRISMA) guidelines..$^{14}$ Our literature search was developed by defining the population, intervention, comparison, outcomes, and study (PICOS) design as summarized in Supplemental Table 1. Search strategy, selection criteria, and outcome measures were determined in advance. No registered review protocol was utilized in this study.

\section{Search Strategy}

We performed electronic searches in PubMed, Google Scholar, Embase, Scopus, Web of Science, Ovid Medline, and Cochrane Library from their dates of inception to December 2020. Medical subject headings and Boolean operators were utilized to capture all relevant literature. Synonymous words such as "brain infarct," "cerebrovascular accident," and "occlusion" for "acute ischemic stroke," and variations of terms such as "stent retriever" and "endovascular treatment" for "mechanical thrombectomy" were utilized to maintain high inclusivity for the initial search. In addition, we conducted manual searches of the reference lists to confirm the full citations.

\section{Selection Criteria}

To be eligible for inclusion in our systematic review and meta-analysis, studies had to meet the following criteria: 1) directly compared outcomes between MT (interventions) and medical management with IV tPA (controls) for patients with AIS; 2) included patients presenting with distal vessel occlusions $\left(A_{2}\right.$ segment of the anterior cerebral artery [ACA], $\mathrm{M}_{3-4}$ segments of the middle cerebral artery [MCA], and $\mathrm{P}_{2-4}$ segments of the posterior cerebral artery [PCA]); and 3) separated angiographic and/or clinical outcomes for patients who underwent MT and those who underwent medical management with IV tPA. Upfront ex- clusion criteria included studies that had fewer than $10 \mathrm{pa}-$ tients with distal occlusions, case reports, review articles, abstract-only papers, in vitro/animal studies, and expert opinions. When there were duplicate studies with overlapping cohorts or increased lengths of follow-up, we only included the most complete reports for quantitative assessment. We did not restrict our search to language, country, patient characteristics, or underlying disease status (i.e., primary disease or recurrent disease).

\section{Data Extraction and Quality Appraisal}

All titles generated by electronic database searches were screened. Two review authors (C.C.K. and M.W.) independently assessed the abstracts of all potentially relevant studies and reported the results in a structured data collection form. Disagreements were resolved by consensus. The following prespecified study characteristics were extracted: first author, year of publication, cohort size of each treatment group, patient age, sex, hypertension, diabetes mellitus, National Institutes of Health Stroke Scale (NIHSS) score at presentation, average time from stroke onset to treatment, type of intervention, 90-day modified Rankin Scale (mRS) score from 0 to 2, occurrence of symptomatic intracerebral hemorrhage (sICH), and 90day mortality rate. The primary endpoint was the proportion of patients achieving a favorable clinical outcome at 90 days after the onset of symptoms, defined as an mRS score between 0 and $2 .{ }^{15}$ The $\mathrm{mRS}$ is a 7-point ordinal scale ranging from 0 (no symptoms) to 6 (death). Clinical safety outcomes included all-cause mortality rates at 90 days posttreatment, and the proportion of patients who experienced sICH as defined in the Safe Implementation of Thrombolysis in Stroke-Monitoring Study (SITS MOST) ${ }^{16}$ Another outcome studied was successful recanalization, defined as Thrombolysis in Cerebral Infarction scale (TICI) grade $2 \mathrm{~b}$ or 3 in patients treated with MT, or otherwise stated in those treated with IVT alone.

Quality and risk of bias of the contributing articles were assessed using the Newcastle-Ottawa Scale (NOS). ${ }^{17}$ It offers capacity in evaluating nonrandomized studies by 8 items within 3 major categories: study population selection, comparability between groups, and outcome. A maximum of 9 stars can be allocated to one study.

\section{Statistical Analysis}

The baseline characteristics and outcomes among patients with distal vessel occlusions treated with either MT or IVT were compared. In our meta-analysis, we calculated relative odds ratios and their corresponding 95\% confidence intervals to measure the effect size of all the outcomes. Heterogeneity across individual studies was assessed using the $\mathrm{I}^{2}$ index and Cochran's Q statistical test. Based on the $\mathrm{I}^{2}$ statistic, values of $25 \%, 50 \%$, and $75 \%$ were considered as yielding low, moderate, and high heterogeneity, respectively. If $\mathrm{I}^{2}$ was $>25 \%$, results using a random-effects model (DerSimonian and Laird method) are presented. If $\mathrm{I}^{2}$ was $<25 \%$, then fixed-effect model results are presented. A funnel plot served as a visual means to assess potential publication bias, and its impact 
TABLE 1. Descriptive summary of included studies in systematic review and meta-analysis

\begin{tabular}{|c|c|c|c|c|c|c|c|c|c|c|}
\hline \multirow[b]{2}{*}{$\begin{array}{l}\text { Authors } \\
\& \text { Year }\end{array}$} & \multirow[b]{2}{*}{ Design* } & \multirow[b]{2}{*}{ Occlusion Site } & \multicolumn{4}{|c|}{ MT } & \multicolumn{4}{|c|}{ IVT } \\
\hline & & & $\begin{array}{l}\text { No. of } \\
\text { Pts (\%) }\end{array}$ & $\begin{array}{l}\text { Age } \\
\text { (yrs) }\end{array}$ & $\begin{array}{c}\text { No. of } \\
\text { Females (\%) }\end{array}$ & $\begin{array}{l}\text { Treatment } \\
\text { Method }\end{array}$ & $\begin{array}{l}\text { No. of } \\
\text { Pts (\%) }\end{array}$ & $\begin{array}{l}\text { Age } \\
\text { (yrs) }\end{array}$ & $\begin{array}{c}\text { No. of } \\
\text { Females (\%) }\end{array}$ & $\begin{array}{c}\text { Treatment } \\
\text { Method }\end{array}$ \\
\hline $\begin{array}{l}\text { Strambo et } \\
\text { al., } 2020^{18}\end{array}$ & $\begin{array}{l}\text { Single } \\
\text { center }\end{array}$ & $\mathrm{P}_{2}$ & $60(43.8)$ & 71 & $8(5.8)$ & $\begin{array}{l}\text { Stent retriever } \\
\text { or ADAPT }\end{array}$ & $12(49.2)$ & 76.6 & $5(2.0)$ & IVT \\
\hline $\begin{array}{l}\text { Sarraj et al., } \\
2018^{19}\end{array}$ & Multicenter & $\begin{array}{l}\text { Distal }\left(M_{2}+M_{3}+M_{4}\right. \\
+A C A), M_{3-4} / A C A\end{array}$ & $37(27.0)$ & 65.8 & $16(11.7)$ & Stent retriever & $70(28.7)$ & 65.4 & $31(12.7)$ & $\begin{array}{c}\text { IV } \\
\text { alteplase }\end{array}$ \\
\hline $\begin{array}{l}\text { Lobsien et } \\
\text { al., } 2016^{21}\end{array}$ & Multicenter & $M_{3}, M_{4}$ & $28(20.4)$ & 67 & $14(10.2)$ & Stent retriever & $59(24.2)$ & 77 & $32(13.1)$ & IVT \\
\hline $\begin{array}{l}\text { Nogueira et } \\
\text { al., } 2016^{20}\end{array}$ & Multicenter & $\mathrm{M}_{3}$ & $70(8.8)$ & 70 & $6(4.4)$ & Stent retriever & $103(42.2)$ & 69 & $51(20.9)$ & IV rt-PA \\
\hline
\end{tabular}

$\mathrm{ADAPT}=\mathrm{a}$ direct aspiration first pass technique; $\mathrm{pt}=$ patient; $r t-\mathrm{PA}=$ recombinant $\mathrm{tPA}$.

${ }^{*}$ All studies were retrospective.

on the results was further examined via Egger's regression asymmetry test. We considered a two-sided $p$ value $<0.05$ to be significant. All statistical analyses were conducted using RStudio software version 1.3.1056, and the metafor and metaFunction package (r-project.org) was used to develop graphics and quantitative measurement in this analysis.

\section{Results}

A systematic search of the literature identified a total of 1396 candidate articles, of which 55 articles were retrieved for full-text evaluation. Ultimately, 4 studies met the inclusion criteria and were included in this review (Table 1). ${ }^{18-21}$ Details of the study flow are illustrated in Fig. 1.

\section{General Characteristics and Methodological Quality of Studies}

A total of 381 consecutive patients were included in our study; 137 received treatment with MT (median age 68.5 years, $32.1 \%$ female, median baseline NIHSS score of 11.5 points), and 244 received IVT alone (median age 72.8 years, $48.8 \%$ female, median baseline NIHSS score of 10.5 points). There were no differences in age, sex, diabetes mellitus, and pooled baseline NIHSS scores between MT and IVT groups ( $\mathrm{p}>0.05)$, whereas hypertension was more prevalent in patients treated with MT $(90.9 \%$ vs $80.6 \%, p=0.005$ ). Table 2 compares baseline characteristics in the two treatment groups.

All included studies were retrospective in design and published between 2016 and 2020; among them, 3 were multicenter studies and 1 was a single-center study. Based on the NOS scores, which ranged from 5 to 7 stars, all included studies have a moderate methodological quality. Most of them enrolled a representative sample of patients, provided an adequate outcome ascertainment and assessment, and had sufficient follow-up of cohorts. Details of quality appraisal are shown in Supplemental Table 2.

\section{Clinical Outcomes}

Information on favorable outcome (mRS scores $0-2$ ) at 90 days was available from all 4 studies. Overall, the rate of favorable outcome was seen in $54.7 \%(\mathrm{n}=75)$ of patients treated with MT devices and 54.5\% $(\mathrm{n}=133)$ of patients receiving IVT. The pooled results showed no significant difference between the MT group and the IVT group (OR 1.16, 95\% CI 0.23-5.93; p = 0.861) (Fig. 2). However, significant heterogeneity was detected across the 4 studies $\left(\mathrm{I}^{2}=88.9 \%, \mathrm{p}<0.01\right)$. The funnel plot, followed by Egger's linear regression test, excluded publication bias ( $\mathrm{p}=$ 0.267 ), although this is not reliable due to the small number of studies (Supplemental Fig. 1).

Symptomatic intracerebral hemorrhage was observed in $5.8 \%(\mathrm{n}=8)$ of patients in the MT group and 2.5\% $(\mathrm{n}=$ 6) of patients in the IVT group. The pooled OR for sICH was 2.45 (95\% CI $0.75-8.03 ; \mathrm{p}=0.140)$ with no statistically significant heterogeneity between trials $\left(\mathrm{I}^{2}=0 \%, \mathrm{p}\right.$ $=0.812$ ) (Fig. 3). Moreover, patients treated with MT versus IVT did not show a statistically significant increased likelihood of intracranial hemorrhage (OR 1.94, 95\% CI $\left.0.80-4.69 ; \mathrm{p}=0.141 ; \mathrm{I}^{2}=0 \%\right)$. Only 3 studies reported a mortality rate at 90 days. ${ }^{18-20}$ No difference in mortality at long-term follow-up was demonstrated in the meta-analysis of pooled data (Fig. 4), with low heterogeneity (OR $1.73,95 \%$ CI $0.66-4.55 ; \mathrm{p}=0.263 ; \mathrm{I}^{2}=0 \%$ ).

\section{Angiographic and Procedural Outcomes}

The median interval from symptom onset to treatment showed a trend toward a longer time in the IVT group compared with the MT group, although the difference was not statistically significant (171.5 vs 164.2 minutes, $p$ $=0.96$ ). The rates of successful recanalization were $58.8 \%$ and $77.0 \%$, respectively (OR $0.96,95 \%$ CI $0.19-4.72 ; p=$ $\left.0.959 ; \mathrm{I}^{2}=80.9 \%\right)$. These data are summarized in Table 3 .

\section{Discussion}

MT has become the standard treatment modality for AIS due to proximal LVOs. However, there are insufficient data to ascertain whether MT is superior to medical management with IV tPA in distal vessel occlusions. In this meta-analysis of patients who underwent MT for distal circulation strokes, $54.7 \%$ of patients achieved a favorable outcome at the 3-month follow-up, with sICHs observed in $5.8 \%$ of patients and a $16.5 \%$ mortality rate. 


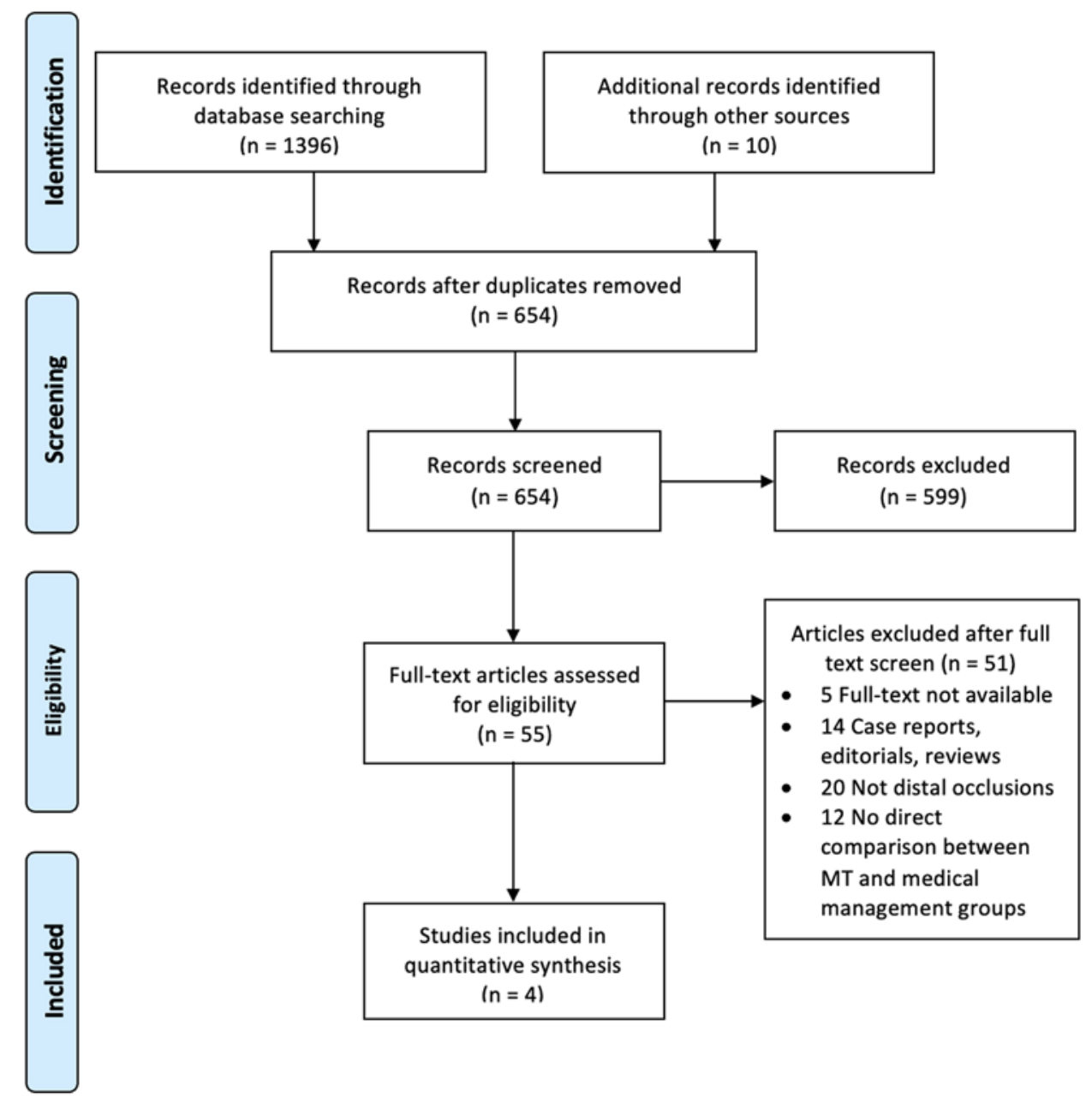

FIG. 1. Search strategy following the PRISMA guidelines.

The rate of favorable outcomes was comparable between patients treated with MT and those treated with IVT (for IVT: favorable outcome, 54.5\%; sICH, 2.5\%; and mortality, $12.4 \%$ ). Smaller-sized vessels, which are more fragile, are known to be associated with higher rates of cerebral hemorrhage when treated endovascularly. A meta-analysis including 1080 patients identified an increased risk of intracranial hemorrhage in distal MCA occlusions compared with that of the $\mathrm{M}_{1}$ segment (OR 3.39). ${ }^{22}$ Although we observed a trend in the rates of sICH and mortality, these did not reach statistical significance. Overall, both treatment approaches showed similar effectiveness and safety in AIS patients with distally located clots.

Concerns relating to the use of MT in treating distally located clots include the challenging navigation of devices to distal vasculature and a higher risk of $\mathrm{SICH}^{1,6}$ In addition, clinical presentations and outcomes of distal occlusion strokes tend to be more favorable due to

TABLE 2. Baseline characteristics of the study population

\begin{tabular}{lccc}
\hline \multicolumn{1}{c}{ Baseline Characteristic } & MT $(\mathrm{n}=137)$ & $\mathrm{IVT}(\mathrm{n}=244)$ & $\mathrm{p}$ Value \\
\hline Median age, yrs (IQR) & $68.5(66.7-70.25)$ & $72.8(68.1-76.7)$ & 0.298 \\
\hline Female & $44 / 137(32.1)$ & $119 / 244(48.8)$ & 0.103 \\
\hline Hypertension & $70 / 77(90.9)$ & $187 / 232(80.6)$ & 0.005 \\
\hline Diabetes mellitus & $29 / 77(37.7)$ & $44 / 232(19.0)$ & 0.443 \\
\hline Median NIHSS admission score (IQR) & $11.5(6.3-16.8)$ & $10.5(6.0-14.8)$ & 0.803 \\
\hline Median onset-to-treatment time, mins (IQR) & $164.2(136.2-206.1)$ & $171.5(135.0-212.5)$ & 0.962 \\
\hline $\begin{array}{l}\text { Values represent the number of patients/total number of patients (\%) unless stated otherwise. Boldface type indicates } \\
\text { statistical significance. }\end{array}$
\end{tabular}




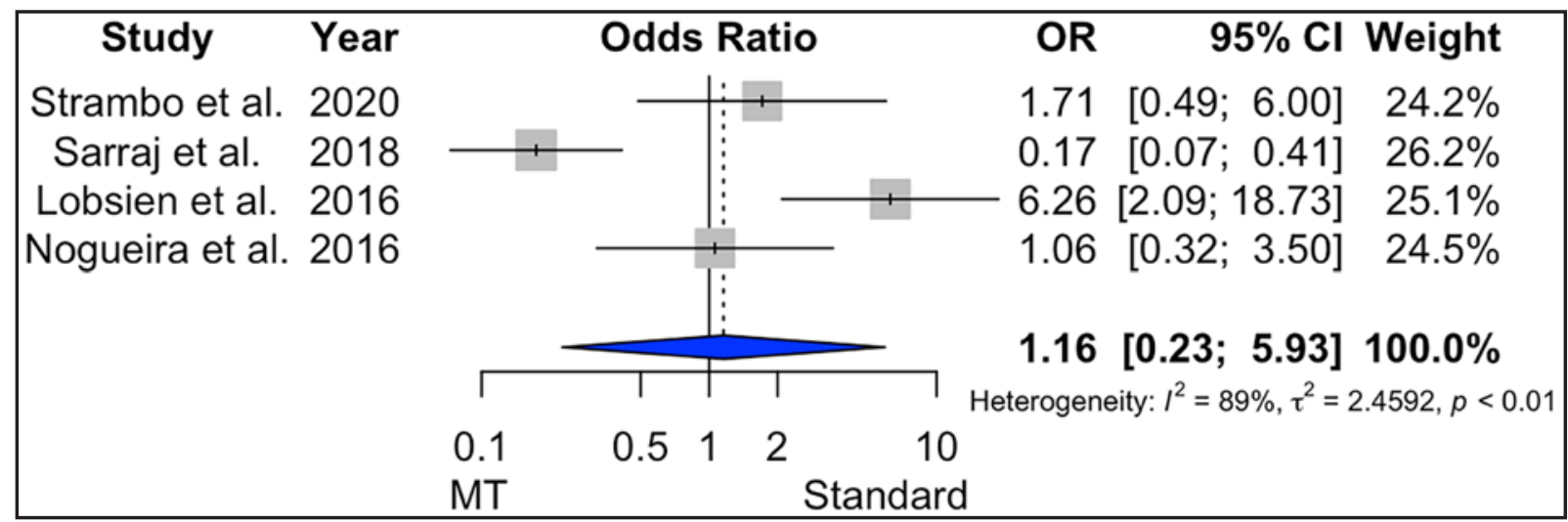

FIG. 2. Forest plot of favorable outcome (mRS scores $0-2$ ) at 90 days posttreatment.

smaller infarct and penumbra volumes, making IV tPA effective in treating these patients. ${ }^{23} \mathrm{~A}$ meta-analysis of 2063 patients reported 52\% partial or complete recanalization with IV tPA alone in distal MCA occlusion compared with $35 \%$ for the $\mathrm{M}_{1}$ segment, $13 \%$ for the internal carotid artery, and $13 \%$ for the basilar artery. ${ }^{24}$ Although more effective for distal than proximal occlusions, IV tPA treatment nonetheless fails to recanalize one-half to twothirds of distal occlusions. ${ }^{25}$ It is also frequently limited by the narrow therapeutic time window and by multiple contraindications. ${ }^{26}$ Due to these limitations, there is a subset of patients with AIS with distal thrombi who may benefit from a more aggressive MT therapy as the firstline treatment.

There is a lack of data from randomized controlled trials to prove the effectiveness of MT for distal intracranial vessel occlusion. In the Interventional Management of Stroke III trial, there were only 5 cases with $\mathrm{M}_{3}, \mathrm{M}_{4}$, or ACA occlusions. ${ }^{27}$ Likewise, the Multicenter Randomized Clinical Trial of Endovascular Treatment for Acute Ischemic Stroke in the Netherlands (MR CLEAN) included only 3 subjects with ACA occlusions. ${ }^{4}$ The remaining randomized controlled trials that established the efficacy of MT for LVO strokes explicitly excluded patients with distal occlusions. ${ }^{1-3}$ Recently, Barchetti et al. performed a meta-analysis and reported that MT in distal locations had an overall good functional outcome rate of $58.8 \%$
(63.7\% in the ADAPT [a direct aspiration first pass technique] group vs $52.0 \%$ in the stent retriever group) at the 3 -month follow-up, and 383 of 494 patients (77.5\%) had a TICI grade of $2 b$ or $3{ }^{28}$ Another comparative study of procedural outcomes according to thrombus location (proximal vs distal) found a similar rate of mRS score from 0 to $2(71.1 \%$ vs $64.7 \%)$, TICI grade $2 \mathrm{~b}$ or 3 ( $88 \%$ vs $89 \%)$, and mortality (12\% vs $8 \%){ }^{29}$ It should be noted that $89 \%$ of the distal locations comprised the $\mathrm{M}_{2}$ segment of the MCA. Despite multiple studies that have reported the feasibility and safety of MT in treating AIS with distal occlusions, none of the studies to date have directly compared treatment outcomes between the MT devices and medical management.

Current AHA/ASA guidelines recommend IV tPA for patients presenting with distal occlusions, and that MT may be justified only in carefully selected cases. ${ }^{6} \mathrm{Al}-$ though not statistically significant, in the current study, the baseline NIHSS score was higher in the MT group than in the IVT group (11.5 vs 10.5), suggesting that endovascular therapy was offered to patients with more severe symptoms. This selection bias is also evident in the retrospective analysis by Grossberg et al., who observed that many MT-treated distal occlusion cases involved multiple vascular territories, were contraindicated to IV tPA, or had dramatic clinical presentation resembling proximal arterial occlusions. ${ }^{10}$ For patients with mild strokes, the

\section{Study Year}

Strambo et al. 2020

Sarraj et al. 2018

Lobsien et al. 2016

Nogueira et al. 2016

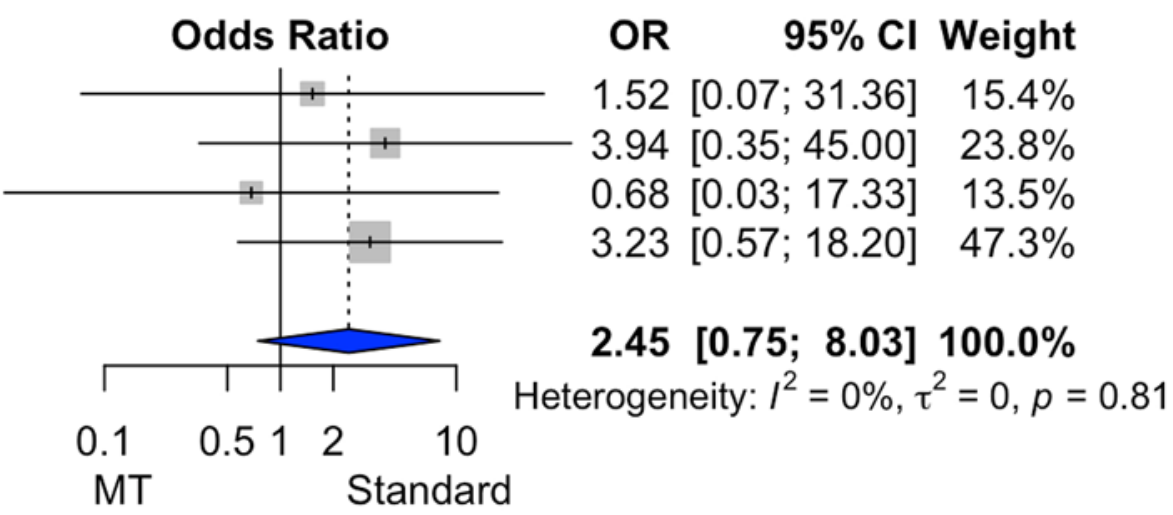

FIG. 3. Forest plot of sICH occurrence. 


$\begin{array}{cc}\text { Study } & \text { Year } \\ \text { Strambo et al. } & 2020 \\ \text { Sarraj et al. } & 2018 \\ \text { Nogueira et al. } & 2016\end{array}$

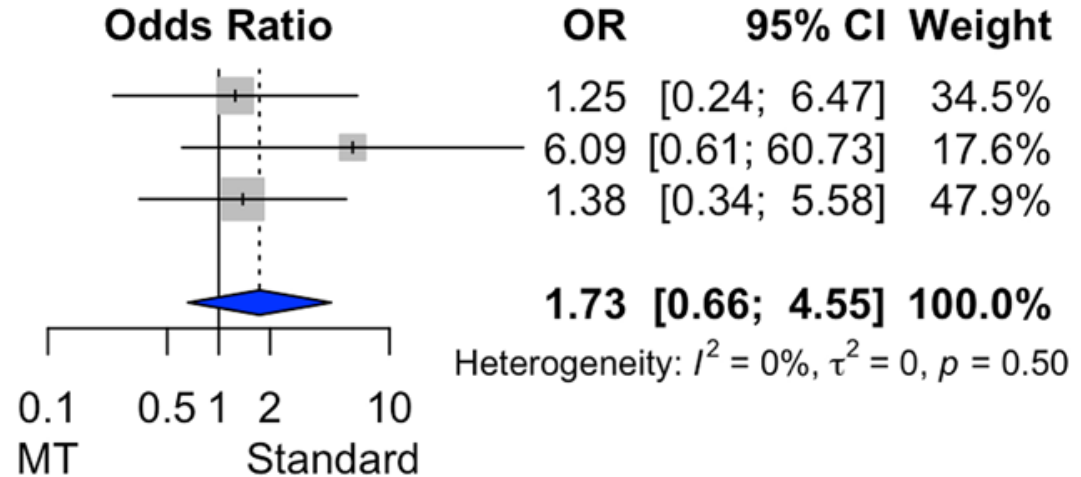
$6.09[0.61 ; 60.73] \quad 17.6 \%$ $1.38[0.34 ; 5.58] \quad 47.9 \%$

\section{$1.73[0.66 ; 4.55] 100.0 \%$}

\section{$\begin{array}{lrrr}0.1 & 0.51 & 2 & 10 \\ \text { MT } & & \text { Standard }\end{array}$}

FIG. 4. Forest plot of mortality at 90 days posttreatment.

rationale to prioritize MT over IVT lies mainly in avoiding early neurological deterioration. ${ }^{30}$ Without sufficient evidence proving the role of endovascular therapy in treating distal occlusions, medical judgment is paramount to ensure that patients with distal vessel occlusions are evaluated for medical management with IV tPA versus MT.

The $\mathrm{M}_{1}$ segment, intracranial internal carotid artery, vertebral artery, and basilar artery are categorized as proximal large arteries, whereas $\mathrm{M}_{3}$ and $\mathrm{M}_{4}$ segments, $\mathrm{A}_{2}$ to $\mathrm{A}_{4}$ segments, and $\mathrm{P}_{2}$ to $\mathrm{P}_{4}$ segments are recognized as distal arteries. Nevertheless, classifying the $M_{2}$ vessel is especially challenging due to its diverse branching patterns and highly heterogeneous angioarchitecture across patients. ${ }^{31}$ In this meta-analysis, we did not include $\mathrm{M}_{2}$ in our distal vessel definition. The nature of the $\mathrm{M}_{2}$ occlusions could have been "proximal, large" $\mathrm{M}_{2}$ that is similar to $\mathrm{M}_{1}$, rather than "distal, small" $\mathrm{M}_{2}$. However, it is worth noting that one of the included studies does include cases with $\mathrm{M}_{2}$ occlusions, since Sarraj et al. include distal $\mathbf{M}_{2}$, $\mathrm{M}_{3}, \mathrm{M}_{4}$, and ACA in the same distal group without specifying numbers of patients for each segment. ${ }^{19}$ A previous study reported that the $\mathrm{M}_{2}$ segment definition and thrombus location can lead to distinct good functional outcomes and revascularization rates. ${ }^{32}$ As such, this is a potential source contributing to the substantial heterogeneity observed in the pooled mRS score of 0 to 2 and successful recanalization.

Some limitations of this meta-analysis must be acknowledged. Despite the inherent constraints of the retrospective observational design in all the included studies, the baseline characteristics between the two treatments were mostly comparable. Patients in the MT group had a higher rate of hypertension, which may bias the outcomes toward a lower MT effect. The heterogeneity for the occurrence of favorable outcome and a TICI grade of $2 b$ or 3 was quite high, reflecting the difference in terminologies and the variability in radiographic evaluation, inclusion criteria, and devices selected according to physician preference. We also did not perform a meta-analysis with adjusted effect sizes for potential covariates since most of the studies did not report them. Moreover, the limited sample size may contribute to our failure in detecting independent associations between treatment approach (MT vs IVT) and outcomes of interest.

\section{Conclusions}

In the management of distal vessel occlusion stroke, the results of the present systematic review and meta-analysis offer evidence that MT is as safe as IVT. Prospective clinical trials are needed to further compare the efficacy of MT versus medical management with IV tPA for distal vessel occlusion.

\section{References}

1. Saver JL, Goyal M, Bonafe A, et al. Stent-retriever thrombectomy after intravenous t-PA vs. t-PA alone in stroke. $N$ Engl J Med. 2015;372(24):2285-2295.

2. Campbell BC, Mitchell PJ, Kleinig TJ, et al. Endovascular therapy for ischemic stroke with perfusion-imaging selection. N Engl J Med. 2015;372(11):1009-1018.

3. Jovin TG, Chamorro A, Cobo E, et al. Thrombectomy within 8 hours after symptom onset in ischemic stroke. $N$ Engl $J$ Med. 2015;372(24):2296-2306.

4. Berkhemer OA, Fransen PS, Beumer D, et al. A randomized trial of intraarterial treatment for acute ischemic stroke. $N$ Engl J Med. 2015;372(1):11-20.

TABLE 3. Outcomes after MT and IVT of patients with AIS and distal occlusions

\begin{tabular}{lcccccc}
\hline & No. of Studies & \multicolumn{1}{c}{ MT } & IVT & OR $(95 \%$ Cl) & p Value & $1^{2}$ \\
\hline Successful recanalization & 3 & $77.0 \%$ & $58.8 \%$ & $0.96(0.19-4.72)$ & 0.959 & $80.9 \%$ \\
\hline Favorable outcomes & 4 & $54.7 \%$ & $54.5 \%$ & $1.16(0.23-5.93)$ & 0.861 & $88.9 \%$ \\
\hline sICH & 4 & $5.8 \%$ & $2.5 \%$ & $2.45(0.75-8.03)$ & 0.140 & $0 \%$ \\
\hline All ICH & 4 & $7.5 \%$ & $5.7 \%$ & $1.94(0.80-4.69)$ & 0.141 & $0 \%$ \\
\hline Mortality & 3 & $16.5 \%$ & $12.4 \%$ & $1.73(0.66-4.55)$ & 0.263 & $0 \%$ \\
\hline
\end{tabular}

$\mathrm{ICH}=$ intracerebral hemorrhage. 
5. Goyal M, Demchuk AM, Menon BK, et al. Randomized assessment of rapid endovascular treatment of ischemic stroke. N Engl J Med. 2015;372(11):1019-1030.

6. Powers WJ, Rabinstein AA, Ackerson T, et al. Guidelines for the Early Management of Patients with Acute Ischemic Stroke: 2019 update to the 2018 Guidelines for the Early Management of Acute Ischemic Stroke: a guideline for healthcare professionals from the American Heart Association/American Stroke Association. Stroke. 2019;50(12):e344e418.

7. Saver JL, Chapot R, Agid R, et al. Thrombectomy for distal, medium vessel occlusions: a consensus statement on present knowledge and promising directions. Stroke. 2020;51(9): 2872-2884.

8. Gascou G, Lobotesis K, Machi P, et al. Stent retrievers in acute ischemic stroke: complications and failures during the perioperative period. AJNR Am J Neuroradiol. 2014;35(4): 734-740.

9. Kunz WG, Almekhlafi MA, Goyal M. Distal vessel occlusions: when to consider endovascular thrombectomy. Stroke. 2018;49(7):1581-1583.

10. Grossberg JA, Rebello LC, Haussen DC, et al. Beyond large vessel occlusion strokes: distal occlusion thrombectomy. Stroke. 2018;49(7):1662-1668.

11. Pfaff J, Herweh C, Pham M, et al. Mechanical thrombectomy of distal occlusions in the anterior cerebral artery: recanalization rates, periprocedural complications, and clinical outcome. AJNR Am J Neuroradiol. 2016;37(4):673-678.

12. Haussen DC, Al-Bayati AR, Eby B, et al. Blind exchange with mini-pinning technique for distal occlusion thrombectomy. J Neurointerv Surg. 2020;12(4):392-395.

13. Onal Y, Velioglu M, Demir U, et al. Feasibility of distal mechanical thrombectomy in M3, A3 and P3 segments via a 0.013 -inch delivery system: preliminary experience. Turk Neurosurg. 2020;30(4):614-620.

14. Moher D, Liberati A, Tetzlaff J, Altman DG. Preferred reporting items for systematic reviews and meta-analyses: the PRISMA statement. Ann Intern Med. 2009;151(4):264-269, W64.

15. van Swieten JC, Koudstaal PJ, Visser MC, et al. Interobserver agreement for the assessment of handicap in stroke patients. Stroke. 1988;19(5):604-607.

16. Wahlgren N, Ahmed N, Dávalos A, et al. Thrombolysis with alteplase for acute ischaemic stroke in the Safe Implementation of Thrombolysis in Stroke-Monitoring Study (SITSMOST): an observational study. Lancet. 2007;369(9558): 275-282.

17. Wells GA, Shea B, O'Connell D, et al. The Newcastle-Ottawa Scale (NOS) for Assessing the Quality of Non-Randomized Studies in Meta-Analysis. The Ottawa Hospital. Accessed May 7, 2021. http://www.ohri.ca/programs/clinical_epidemiology/oxford.asp

18. Strambo D, Bartolini B, Beaud V, et al. Thrombectomy and thrombolysis of isolated posterior cerebral artery occlusion: cognitive, visual, and disability outcomes. Stroke. 2020;51(1): 254-261.

19. Sarraj A, Hassan A, Savitz SI, et al. Endovascular thrombectomy for mild strokes: how low should we go? Stroke. 2018; 49(10):2398-2405.

20. Nogueira RG, Zaidat OO, Castonguay AC, et al. Rescue thrombectomy in large vessel occlusion strokes leads to better outcomes than intravenous thrombolysis alone: a 'real world' applicability of the recent trials. Intervent Neurol. 2016;5(3-4):101-110.

21. Lobsien D, Gawlitza M, Schaudinn A, et al. Mechanical thrombectomy versus systemic thrombolysis in MCA stroke: a distance to thrombus-based outcome analysis. J Neurointerv Surg. 2016;8(9):878-882.

22. Saber H, Narayanan S, Palla M, et al. Mechanical throm- bectomy for acute ischemic stroke with occlusion of the M2 segment of the middle cerebral artery: a meta-analysis. $J$ Neurointerv Surg. 2018;10(7):620-624.

23. del Zoppo GJ, Poeck K, Pessin MS, et al. Recombinant tissue plasminogen activator in acute thrombotic and embolic stroke. Ann Neurol. 1992;32(1):78-86.

24. Seners P, Turc G, Maïer B, et al. Incidence and predictors of early recanalization after intravenous thrombolysis: a systematic review and meta-analysis. Stroke. 2016;47(9):2409-2412.

25. Furlan A, Higashida R, Wechsler L, et al. Intra-arterial prourokinase for acute ischemic stroke. The PROACT II study: a randomized controlled trial. Prolyse in Acute Cerebral Thromboembolism. JAMA. 1999;282(21):2003-2011.

26. Peña ID, Borlongan C, Shen G, Davis W. Strategies to extend thrombolytic time window for ischemic stroke treatment: an unmet clinical need. J Stroke. 2017;19(1):50-60.

27. Demchuk AM, Goyal M, Yeatts SD, et al. Recanalization and clinical outcome of occlusion sites at baseline CT angiography in the Interventional Management of Stroke III trial. Radiology. 2014;273(1):202-210.

28. Barchetti G, Cagnazzo F, Raz E, et al. Mechanical thrombectomy of distal occlusions using a direct aspiration first pass technique compared with new generation of mini-0.017 microcatheter compatible-stent retrievers: a meta-analysis. World Neurosurg. 2020;134:111-119.

29. Sweid A, Head J, Tjoumakaris S, et al. Mechanical thrombectomy in distal vessels: revascularization rates, complications, and functional outcome. World Neurosurg. 2019;130: e1098-e1104.

30. Mazya MV, Cooray C, Lees KR, et al. Minor stroke due to large artery occlusion. When is intravenous thrombolysis not enough? Results from the SITS International Stroke Thrombolysis Register. Eur Stroke J. 2018;3(1):29-38.

31. Waqas M, Rai AT, Vakharia K, et al. Effect of definition and methods on estimates of prevalence of large vessel occlusion in acute ischemic stroke: a systematic review and meta-analysis. J Neurointerv Surg. 2020;12(3):260-265.

32. Tomsick TA, Carrozzella J, Foster L, et al. Endovascular therapy of M2 occlusion in IMS III: role of M2 segment definition and location on clinical and revascularization outcomes. AJNR Am J Neuroradiol. 2017;38(1):84-89.

\section{Disclosures}

Dr. Levy: shareholder/ownership interests in NeXtGen Biologics, RAPID Medical, Claret Medical, Cognition Medical, Imperative Care (formerly the Stroke Project), Rebound Therapeutics, StimMed, and Three Rivers Medical; national principal investigator/steering committees for Medtronic (merged with Covidien Neurovascular) SWIFT Prime and SWIFT Direct trials; honoraria from Medtronic (training and lectures) and Penumbra; consultant for Claret Medical, GLG Consulting, Guidepoint Global, Imperative Care, Medtronic, Rebound, and StimMed; advisory board of Stryker (AIS Clinical Advisory Board), NeXtGen Biologics, MEDX, Cognition Medical, and Endostream Medical; and site principal investigator for the CONFIDENCE study (MicroVention) and STRATIS Study-Sub I (Medtronic). Dr. Siddiqui: financial interest/investor/stock options/ownership in Adona Medical, Amnis Therapeutics (purchased by Boston Scientific in October 2017), Bend IT Technologies, Blink TBI, Boston Scientific Corp. (for purchase of Claret Medical), Buffalo Technology Partners, Cardinal Consultants Cerebrotech Medical Systems, Cognition Medical, Endostream Medical, Imperative Care, Instylla, International Medical Distribution Partners, IRRAS, LaunchNY Seed Fund Management, NeuroRadial Technologies, Neurovascular Diagnostics, Perflow Medical, Q'Apel Medical, Radical Catheter Technologies, Rebound Therapeutics (purchased by Integra LifeSciences in 2019), Rist Neurovascular, Sense Diagnostics, Serenity Medical, Silk Road Medical, Spinnaker Medi- 
cal, StimMed, Synchron, Three Rivers Medical, Truvic Medical, Vastrax, VICIS, Viseon, and Viz.ai; consultant/advisory board for Amnis Therapeutics, Boston Scientific, Canon Medical Systems USA, Cardinal Health 200, Cerebrotech Medical Systems, Cerenovus, Corindus, Endostream Medical, Imperative Care, Integra LifeSciences, IRRAS, Medtronic, MicroVention, Minnetronix Neuro, Northwest University-DSMB Chair for HEAT Trial, Penumbra, Q'Apel Medical, Rapid Medical, Rebound Therapeutics Corp. (purchased by Integra LifeSciences), Serenity Medical, Silk Road Medical, StimMed, Stryker, Three Rivers Medical, VasSol, Viz.ai, and W.L. Gore \& Associates; and principal investigator/ steering committee for the following trials: Cerenovus NAPA and ARISE II; Medtronic SWIFT PRIME and SWIFT DIRECT; MicroVention FRED \& CONFIDENCE; MUSC POSITIVE; and Penumbra 3D Separator, COMPASS, INVEST, and TIGER.

\section{Author Contributions}

Conception and design: Waqas, Dossani. Acquisition of data: Waqas, Kuo. Analysis and interpretation of data: Waqas, Kuo. Drafting the article: Waqas, Kuo. Critically revising the article:
Siddiqui, Waqas, Dossani, Monteiro, Alkhaldi, Cappuzzo, Levy. Reviewed submitted version of manuscript: Siddiqui, Dossani, Monteiro. Statistical analysis: Kuo Administrative/technical/material support: Waqas, Monteiro, Baig, Alkhaldi. Study supervision: Siddiqui, Waqas, Cappuzzo, Levy.

\section{Supplemental Information}

Online-Only Content

Supplemental material is available online.

Supplemental Fig. 1 and Tables 1 and 2. https://thejns.org/doi/ suppl/10.3171/2021.4.FOCUS21139.

\section{Correspondence}

Adnan H. Siddiqui, University at Buffalo, NY. asiddiqui@ ubns.com. 